\title{
Opiates Modulate Noxious Chemical Nociception through a Complex Monoaminergic/Peptidergic Cascade
}

\author{
Holly Mills, Amanda Ortega, Wenjing Law, Vera Hapiak, Philip Summers, Tobias Clark, and Richard Komuniecki \\ Department of Biological Sciences, University of Toledo, Toledo, Ohio 43606
}

The ability to detect noxious stimuli, process the nociceptive signal, and elicit an appropriate behavioral response is essential for survival. In Caenorhabditis elegans, opioid receptor agonists, such as morphine, mimic serotonin, and suppress the overall withdrawal from noxious stimuli through a pathway requiring the opioid-like receptor, NPR-17. This serotonin- or morphine-dependent modulation can be rescued in $n p r-17$-null animals by the expression of $n p r-17$ or a human $\kappa$ opioid receptor in the two ASI sensory neurons, with ASI opioid signaling selectively inhibiting ASI neuropeptide release. Serotonergic modulation requires peptides encoded by both $n l p-3$ and $n l p-24$, and either $n l p-3$ or $n l p-24$ overexpression mimics morphine and suppresses withdrawal. Peptides encoded by $n l p-3$ act differentially, with only NLP-3.3 mimicking morphine, whereas other $n l p-3$ peptides antagonize NLP-3.3 modulation. Together, these results demonstrate that opiates modulate nociception in Caenorhabditis elegans through a complex monoaminergic/peptidergic cascade, and suggest that this model may be useful for dissecting opiate signaling in mammals.

Key words: neuropeptide; opiate; pain; serotonin

Significance Statement

Opiates are used extensively to treat chronic pain. In Caenorhabditis elegans, opioid receptor agonists suppress the overall withdrawal from noxious chemical stimuli through a pathway requiring an opioid-like receptor and two distinct neuropeptideencoding genes, with individual peptides from the same gene functioning antagonistically to modulate nociception. Endogenous opioid signaling functions as part of a complex, monoaminergic/peptidergic signaling cascade and appears to selectively inhibit neuropeptide release, mediated by a $\alpha$-adrenergic-like receptor, from two sensory neurons. Importantly, receptor null animals can be rescued by the expression of the human $\kappa$ opioid receptor, and injection of human opioid receptor ligands mimics exogenous opiates, highlighting the utility of this model for dissecting opiate signaling in mammals.

\section{Introduction}

The modulation of pain is complex, and how we perceive and respond to painful stimuli is dependent upon context or behavioral state. Neuromodulators, such as noradrenaline, serotonin (5-HT), and a host of neuropeptides, including endorphins, can alter both the perception and response to painful stimuli within an unchanging anatomical context. To better understand the role

Received Dec. 18, 2015; revised April 7, 2016; accepted April 13, 2016.

Author contributions: H.M. and R.K. designed research; H.M., A.O., W.L., V.H., P.S., and T.C. performed research; R.K. contributed unpublished reagents/analytic tools; H.M. and R.K. analyzed data; H.M. and R.K. wrote the paper. This work was supported by National Institutes of Health Grant A-144147 and Gates Foundation Grant OPP1087209 R.K.

The authors declare no competing financial interests.

Correspondence should be addressed to Dr. Richard Komuniecki, Department of Biological Sciences, University of Toledo, 2801 W Bancroft Street, Toledo, OH 43606. E-mail: rkomuni@uoft02.utoledo.edu.

H. Mills' current address: Department of Molecular Neurobiology, Skirball Institute of Biomolecular Medicine, New York University School of Medicine, New York, New York 10016.

V. Hapiak's current address: Department of Biology, Brandeis University, Waltham, Massachusetts 02453.

P. Summers' current address: Life Sciences Institute, University of Michigan, Ann Arbor, Michigan 49209.

DOI:10.1523/JNEUROSCI.4520-15.2016

Copyright $\odot 2016$ the authors $\quad 0270-6474 / 16 / 365498-11 \$ 15.00 / 0$ of neuromodulators in the context-dependent perception of noxious stimuli, we have examined the role of opiates in the modulation of aversive behavior mediated by the two nociceptive Caenorhabditis elegans ASH sensory neurons. In C. elegans, behavioral state or "context" is largely defined by food availability and is translated by both synaptic and extrasynaptic monoaminergic/peptidergic signaling to modulate the sensory-mediated locomotory decision-making associated with nociception (Komuniecki et al., 2014). The ASHs are primary sensors for chemical repellents, high osmolarity, and mechanical stimulation, all of which elicit a rapid avoidance response. For example, the activation of ASH glutamatergic signaling by 1-octanol increases ASH somal $\mathrm{Ca}^{2+}$ and initiates a complex aversive response involving an initial backward locomotion, followed by reversal and movement away from the noxious source that is usually accompanied by an $\omega$ turn. In contrast, although food or 5-HT stimulates the initiation of this initial backward locomotion, they induce animals to back up less and continue forward after backward locomotion is complete (i.e., animals will move forward and feed even in the face of a noxious odorant). Food and 5-HT have been 
proposed to stimulate the aversive response, based on a more rapid initiation; however, they actually desensitize the animal to aversive stimulus by minimizing the initial backward response and inducing forward locomotion (Summers et al., 2015). This food or 5-HT "desensitization" requires the expression of neuropeptides encoded by $n l p-3$ in the ASHs, as $n l p-3$ null animals can be rescued by ASH $n l p-3$ expression and ASH $n l p-3$ RNAi knockdown abolishes 5-HT modulation in wild-type animals (Chao et al., 2004; Harris et al., 2009, 2010).

C. elegans ASHs and mammalian nociceptive neurons exhibit important similarities (Salt and Hill, 1983; Otsuka and Yoshioka, 1993; Nathoo et al., 2001; Mellem et al., 2002; Harris et al., 2010). In mammals, the noradrenergic inhibition of chronic pain involves the inhibition of afferent pain receptors through $\mathrm{G}_{\mathrm{o}^{-}}$ coupled $\alpha 2$-adrenergic receptors and the release of inhibitory neuropeptides mediated by $\mathrm{G} \alpha$-coupled $\alpha 1$-receptors. A similar system operates in the $C$. elegans ASI sensory neurons, with tyramine (TA)/octopamine (OA) replacing epinephrine/norepinephrine. For example, in C. elegans, the TA-dependent modulation of nociception involves, and the release of neuropeptides from the ASIs mediated by, a TA-dependent $\alpha$-adrenergic-like receptor TYRA-3 (Hapiak et al., 2013).

In the present study, we have demonstrated that $C$. elegans contains an opioid signaling system and an opioid-like receptor, NPR-17, which modulates nociception. For example, opioid receptor agonists, such as morphine mimic 5-HT, stimulate an initial withdrawal from a noxious odorant. However, after this initial withdrawal is complete, opiate receptor agonists also desensitize the aversive response and induce animals to continue forward toward the noxious odorant. Importantly, the morphine and 5-HT sensitivity can be rescued in $n p r-17$-null animals by the expression of a human $\kappa$-opioid receptor, OPKR-1, suggesting that $C$. elegans contain endogenous OPKR-1 ligands. 5-HT modulation requires neuropeptides encoded by both $n l p-3$ and $n l p-$ 24 , with ASI $n l p-24$ peptides activating ASI NPR-17 directly to selectively inhibit the release of a subset of ASI peptides, mediated by the $\alpha$-adrenergic-like receptor TYRA-3 to modulate aversive responses to 1-octanol. Only one of three nlp-3 neuropeptides, NLP-3.3, mimics 5-HT, with the others antagonizing NLP-3.3dependent phenotypes, demonstrating that distinct peptides encoded by the same gene can have different functions. These results demonstrate that $C$. elegans contains an endogenous opioid signaling system that modulates chemical nociception through a monoaminergic/peptidergic signaling cascade, involving serotonergic, adrenergic, and multiple peptide receptors. In addition, they emphasize that perception is not hard-wired, and highlight the utility of the C. elegans model in dissecting these complex, dynamic modulatory circuits.

\section{Materials and Methods}

Materials. Restriction enzymes were purchased from New England Biolabs. NLP-3 neuropeptides were purchased from Neo-peptide. Salvinorin A was purchased from Tocris Bioscience. A plasmid containing the human $\kappa$ opioid receptor cDNA was purchased from Open Bioscience. All other chemicals were purchased from Sigma-Aldrich, including morphine sulfate salt pentahydrate, naloxone, norbinaltorphimine, Dynorphin A, tyramine and octopamine hydrochloride, serotonin creatine sulfate complex, and 1-octanol. cDNA pools were constructed from mixed-stage C. elegans mRNA using standard techniques. GFP reporter constructs were obtained from Andy Fire (Carnegie Institute of Washington, Washington, DC).

Strains. General techniques for the culture and handling of worms have been described (Brenner, 1974). The Bristol N2 strain was used as wild-type. Strains obtained from the Caenorhabditis Genetics Center
(University of Minnesota) include $n l p-24$ (tm2105), $n l p-3$ (tm2302), and $n p r-17$ (tm3210) were received from the National Bio-Resources Project (Tokyo Women's Medical University). The double mutants $n l p-3$ (tm2302);npr-17 (tm3210) were constructed using standard genetic techniques. All mutant animals were backcrossed with the N2 Bristol strain at least $4 \times$ before use in assays or crosses.

Molecular biology and transgenesis. cDNA or genomic regions corresponding to the entire coding sequences of $n l p-3, n l p-24, n p r-17$, and $o p k r-1$ were amplified by PCR and expressed under neuron-selective promoters where indicated. Neuron-selective rescue constructs were created by overlap fusion PCR (Hobert, 2002). Transcriptional fusion constructs for $n p r-17:: g f p$ localization were created by using $5 \mathrm{~kb}$ upstream PCR fusion. Neuron-selective RNAi constructs were created as previously described (Esposito et al., 2007). PCR products were pooled from at least three separate PCRs and coinjected with a selectable marker ( myo-3::gfp, unc-122::rfp or F25B3.3::gfp) and carrier DNA into gonads of C. elegans wild-type or mutant animals by standard techniques (Kramer et al., 1990; Mello and Fire, 1995). Selective expression was achieved using ceh-2 (Aspöck et al., 2003), flp-8 (Kim and Li, 2004), glr-1(Brockie et al., 2001), gpa-4 (2.6kb); npr-9 (1.9 kb), odr-2b (Chou et al., 2001), opt-3 (Fei et al., 2000), tdc-1 (Alkema et al., 2005), unc-53 (Stringham et al., 2002), flp-5 (Kim and Li, 2004), $g c y-33$ (Gross et al., 2014), gpa-9 (Jansen et al., 1999), sra-6 (3.3 kb), str-1 (Troemel et al., 1995), and srg-47 (McGrath et al., 2011).

Behavioral assays. All experiments used age-matched, well-fed young, hermaphrodite adults grown at $20^{\circ} \mathrm{C}$ on standard nematode growth medium, seeded with Escherichia coli strain OP50. 1-Octanol avoidance was assayed as described previously (Chao et al., 2004). Briefly, fourth-stage larvae were picked $24 \mathrm{~h}$ before testing and maintained at $20^{\circ} \mathrm{C}$. Nematode growth medium plates were prepared the morning of the experiment by adding serotonin, tyramine, or octopamine (final concentration, $4 \mathrm{~mm}$ ) to liquid nematode growth medium before pouring. Morphine (320 $\mu \mathrm{M})$, salvinorin A $(320 \mu \mathrm{M})$, naloxone $(320 \mu \mathrm{M})$, or nor-BNI $(320 \mu \mathrm{M})$ was spread on top of test plates immediately before incubation. Dilute (30\%) 1-octanol was prepared daily using 100\% ethanol (v/v). For assays, animals were placed on an unseeded nematode growth medium transfer plate to minimize bacteria carryover, and then transferred to fresh test plates and incubated for $10 \mathrm{~min}$ (off food), $20 \mathrm{~min}$ (morphine, salvinorin A), or $30 \mathrm{~min}$ (serotonin, naloxone, octopamine, tyramine) before assay. Five animals were placed on each plate, and the blunt end of a hair (Loew-Cornell series 8 paintbrush) dipped in 1-octanol was placed in front of a forward moving animal after it just reversed. The time taken to reverse during a $20 \mathrm{~s}$ exposure to 1 -octanol was recorded, as wild-type $C$. elegans spontaneously reverse on average every $20 \mathrm{~s}$.

Peptide injections. NLP-3.1,2,3 peptides and Dynorphin A were diluted in electrophysiology external buffer $(150 \mathrm{~mm} \mathrm{NaCl}, 5 \mathrm{~mm} \mathrm{KCl}, 5 \mathrm{~mm}$ $\mathrm{CaCl}_{2}, 1 \mathrm{~mm} \mathrm{MgCl}_{2}, 10 \mathrm{~mm}$ glucose, 15 mм HEPES, pH 7.30, 327-333 mOsm) from a $10^{-3} \mathrm{M}$ stock solution and were injected into test animals close to the nerve ring at a concentration of $10^{-6} \mathrm{M}$. Injected animals were placed on nematode growth medium test plates and allowed to recover for $10 \mathrm{~min}$ before assay. Mock-injected animals served as controls.

Microscopy and image analysis. Transcriptional and translational transgenes for $n p r-17:: g f p$ and $n l p-24:: g f p$ were generated by PCR fusion (Hobert, 2002). PCR products were pooled from at least three separate PCRs and coinjected with a selectable marker (unc-122:: $r f p$ or rol-6) by standard techniques. Uptake of $1,1^{\prime}$-dioctadecyl-3,3,3',3'-tetramethylindodicarbocyanine (DiD) to identify a subset of amphid sensory neurons capable of dye uptake was assayed as described previously (Herman and Hedgecock, 1990). Briefly, a stock solution (1 mM) of DiD (Invitrogen, Labeling and Detection) was diluted 1:200 in M9 buffer. Larval stage 4 (L4) animals were incubated in $100 \mu \mathrm{l}$ of diluted DiD for $1 \mathrm{~h}$ at room temperature, transferred to a fresh nematode growth medium seeded with OP50 and allowed to crawl on the bacterial lawn for $1-2 \mathrm{~h}$ to destain, and were then placed on $2.5 \%$ agarose pads with $2 \mu \mathrm{l}$ sodium azide ( $10 \mathrm{~mm}$ ) for visualization. At least three transformed lines were analyzed for $g f p$ fluorescence and DiD staining using an Olympus IX81 confocal microscope. 


\section{Results}

Opiates modulate nociception through an opioid-like receptor, NPR-17

The neuropeptide receptor NPR-17 is essential for the food or 5-HT modulation of aversive responses to 1-octanol (Harris et al., 2010). Indeed, upon exposure to dilute 1-octanol, 5-HT (1) stimulated the initiation of the aversive response and (2) induced animals to move forward after backward locomotion was complete but had no effect on these three parameters in npr-17-null animals (Fig. 1A,B). Conversely, $n p r-17$ overexpression from its native promoter mimicked 5-HT (Fig. 1A).

NPR-17 is conserved among nematodes and is most closely related to $C$. brenneri CBN-NPR-17 (89\% identity; E value 0.0$)$ and in the distantly related nematode Brugia malayi (69\% amino acid identity; E value $\left.2 \times 10^{-170}\right)$. In addition, NPR-17 is more distantly related to the human KOR (24\% identity; E value $1 \times$ $\left.10^{-12}\right)$, with greater identity in the transmembrane domains (30\%), and recent work has suggested that NPR-17 functions as an opiate receptor to modulate feeding (Cheong et al., 2015).

Opiates, such as morphine, inhibit nociceptive signals in C-fibers in response to chemical stimuli (Morgan et al., 2006; Alizadeh et al., 2014). Like C-fibers, the ASHs are polymodal, unmyelinated, and express a TRP channel. Therefore, to determine whether C. elegans has an endogenous opioid signaling system modulating nociception, wild-type animals were incubated with morphine, a broad-spectrum opioid receptor agonist and salvinorin $\mathrm{A}$, a selective $\mathrm{KOR}$ agonist. Both morphine and salvinorin $\mathrm{A}$ mimicked 5-HT and stimulated the initiation of the aversive response and induced animals to move forward after the initial backward locomotion was complete (Fig. $2 A, B)$. Conversely, naloxone, a high-affinity MOR antagonist that also antagonizes KOR and DOR and norbinaltorphimine (nBNI), a selective KOR antagonist, abolished the 5-HT modulation of aversive responses (Fig. 2A). Morphine or salvinorin A had no effect on aversive responses to 1-octanol in $n p r-17$-null animals (Fig. 2A). Importantly, although morphine and 5-HT decreased the time taken to initiate withdrawal from a noxious stimulus and induced the animals to move forward after initiation, instead of initiating an $\omega$ turn and reversing away, consistent in keeping with an overall hypothesis of morphineinduced pain suppression.

NPR-17 functions in multiple sensory neurons, including the ASIs, to modulate aversive responses to 1-octanol We have previously reported that NPR-17 is expressed in a subset of head and tail neurons, including the AUAs and PVPs (Harris et (two-tailed Student's $t$ test).
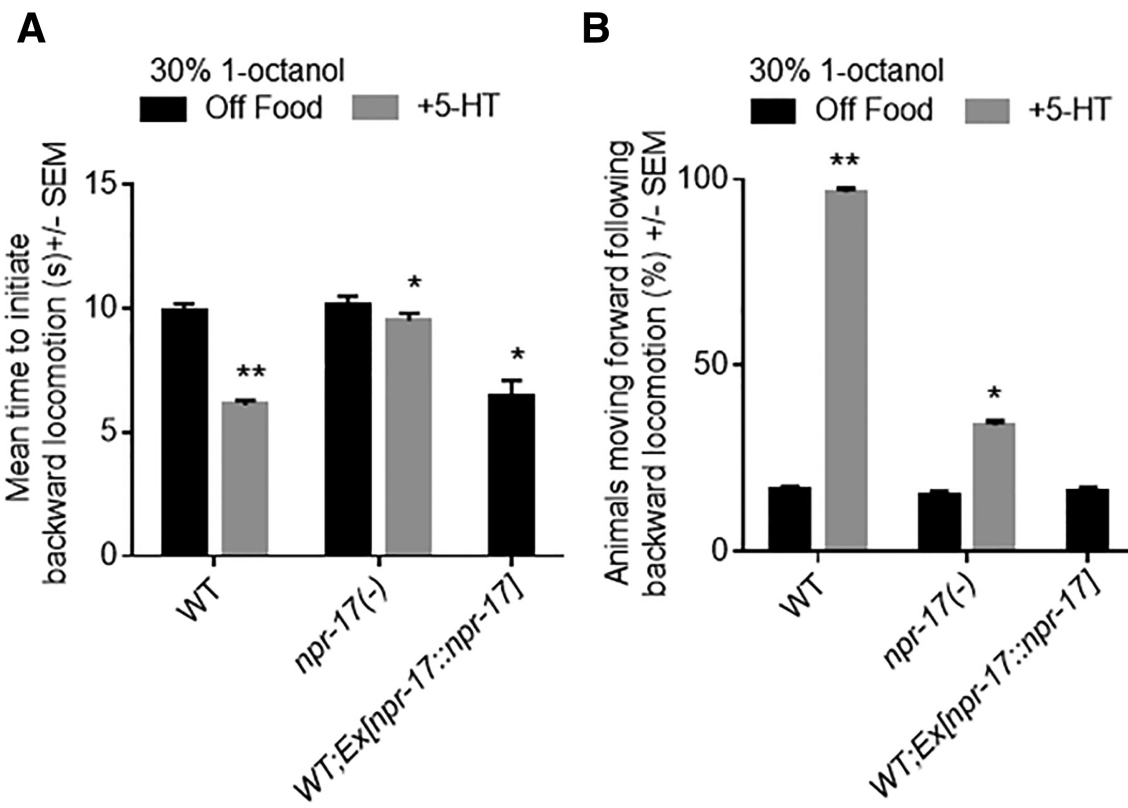

Figure 1. NPR-17 is essential for 5-HT-mediated 1-octanol avoidance. $\boldsymbol{A}, \boldsymbol{B}$, Aversive responses to 1-octanol were measured in the presence and absence of 4 mM 5-HT in wild-type, npr-17-null, and transgenic animals. Data are mean \pm SEM, with 15-20 animals being tested in three independent experiments. ${ }^{*} p<0.0001$, significantly different from wild-type animals under identical conditions (two-tailed Student's $t$ test). ${ }^{* *} p<0.0001$, significantly different from same strain under different conditions

A

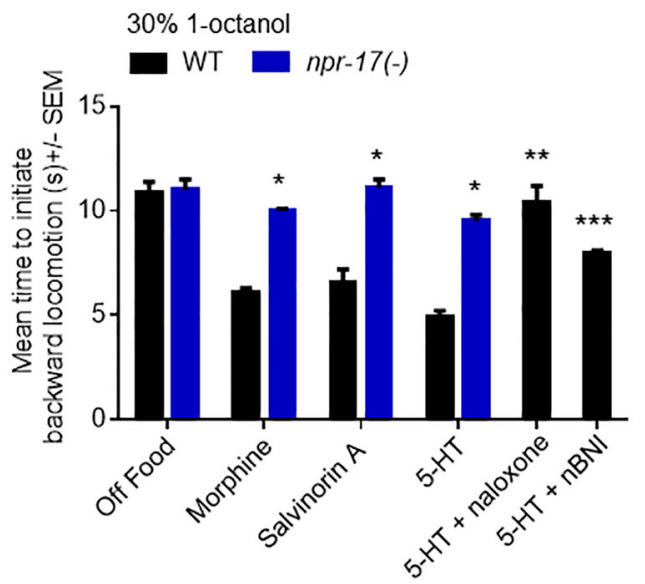

Figure 2. NPR-17 is required for responses to opiate receptor agonists. $\boldsymbol{A}$, Aversive responses to 1-octanol were measured in the presence and absence of $4 \mathrm{~mm} 5-\mathrm{HT}, 320 \mu \mathrm{m}$ morphine, $320 \mu \mathrm{m}$ salvinorin A, or $320 \mu \mathrm{m}$ naloxone and $4 \mathrm{~mm} 5-\mathrm{HT}$ or $320 \mu \mathrm{m} \mathrm{nBNI}$, and $4 \mathrm{~mm} 5$-HT in wild-type and npr-17-null animals. $\boldsymbol{B}$, Postaversive responses were measured as described previously (Summers et al., 2015) in the presence or absence of $320 \mu \mathrm{m}$ morphine. Data are mean \pm SEM, with 15-20 animals being tested in three independent experiments. ${ }^{*} p<0.0001$, significantly different from wild-type animals under identical conditions (two-tailed Student's $t$ test). ${ }^{* *} p=0.0009$, significantly different from wild-type animals on 5 -HT (two-tailed Student's $t$ test). ${ }^{* *} p=$ 0.0014 , significantly different from wild-type animals on 5-HT (two-tailed Student's $t$ test). al., 2010). Additional analysis has also identified npr-17::gfp expression in the ASIs (Fig. $3 A, B$ ). To functionally localize NPR17-dependent modulation, $n$ pr-17 was selectively knocked down using RNAi in neurons expressing $n p r-17:: g f p$, as well as additional neurons within the ASH-locomotory circuit. RNAi knockdown from this minimal npr-17 promoter mimicked the $n p r-17$ null phenotype. The RNAi knockdown of npr-17 using two different promoters whose expression overlap in either the AUAs ( $f l p-8, c e h-6)$, PVPs $(o d r-2 b, u n c-54)$, or ASIs ( gpa-4 or srg-47) largely abolished 5-HT modulation (Fig. 3C). Surprisingly, 
A

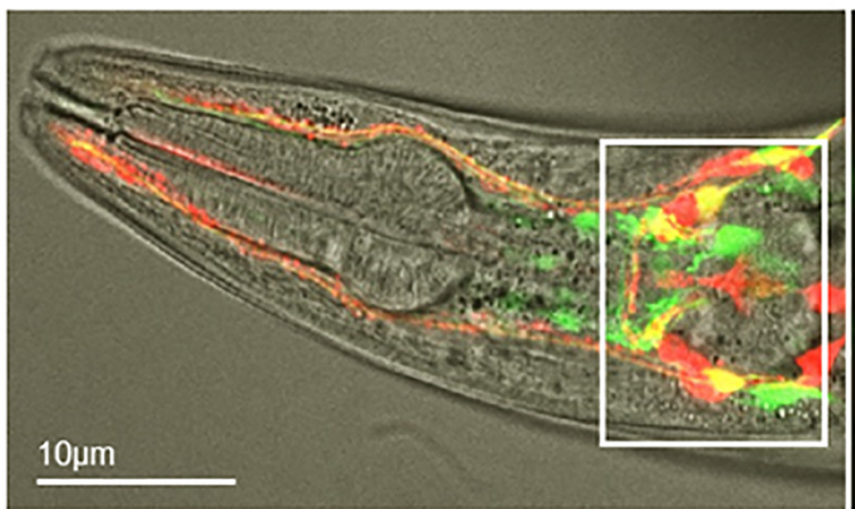

B

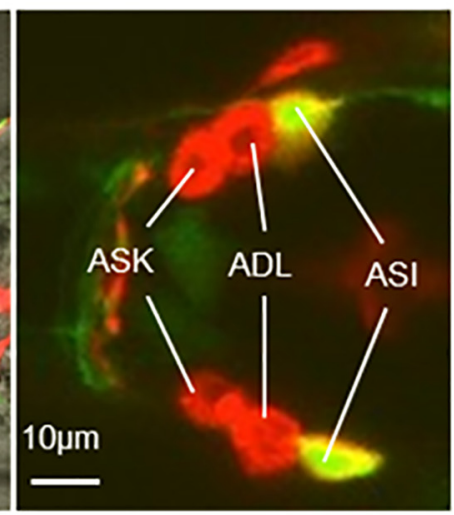

c

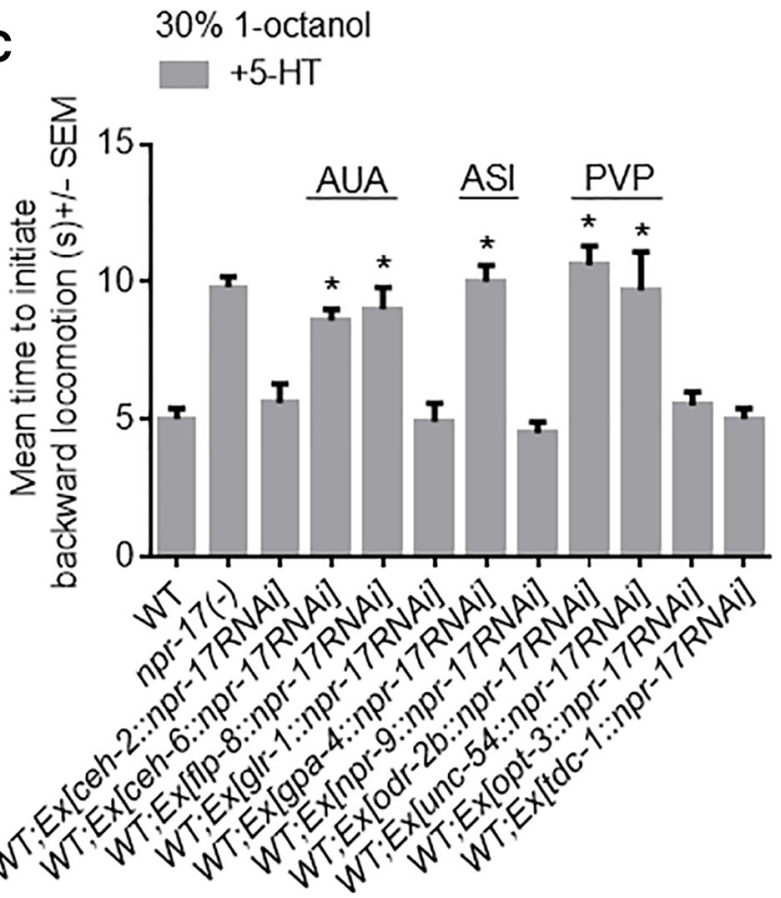

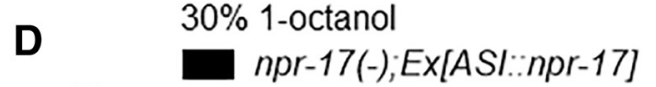

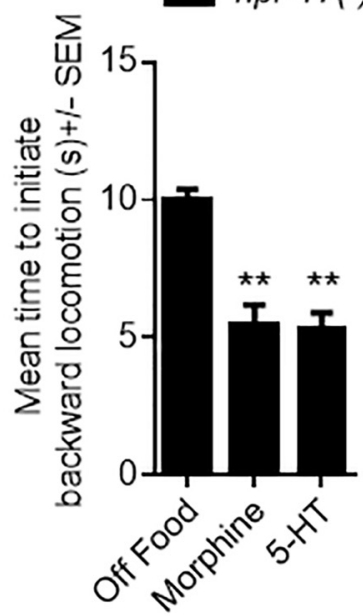

Figure 3. NPR-17 expression in the ASIs is necessary and sufficient for aversive responses to dilute 1-octanol. $\boldsymbol{A}$, Florescence from wild-type animals expressing an $n p r-17:: g f p$ transcriptional reporter merged with DiD staining by confocal microscopy. $\boldsymbol{B}, \mathbf{z}$-Section from $\boldsymbol{A}$, inset. $\boldsymbol{C}, \boldsymbol{D}$, Aversive responses to 1 -octanol were measured in the presence and absence of 4 mM 5 - $H$ T or $320 \mu M$ morphine in wild-type, npr-17-null, and transgenic animals. Ceh-2 (NSM, I3, M3, M4) (Aspöck et al., 2003); flp-8 (ADA, AUA, PVM, RMG,URX); glr-1 (AVA, AVB, AVD, AVE, PVC, AIB, RMD, RIM, SMD, AVG, PVQ, URY); gpa-4 (ASI); npr-9 (AIB); odr-2b (AIB, AIZ, ASG, AVG, IL2, PVP, RIF, RIV, SIAV); opt-3 (AVA); tdc-1 (RIC, RIM); unc-53 (ALN, PLN, PVP, PVQ, BDU, PVM, PDE). Data are mean \pm SEM, with $15-20$ animals being tested in three independent experiments. ${ }^{*} p<0.0001$, significantly different from wild-type animals under identical conditions (two-tailed Student's $t$ test). ${ }^{* *} p<0.0001$, significantly different from animals carrying the same transgene under different conditions (two-tailed Student's $t$ test).

npr-17 expression in the ASIs alone was sufficient to rescue 5-HT or morphine-dependent modulation in npr-17-null animals (Fig. $3 D$ ). This phenomenon where RNAi knockdown in one pair of neurons is sufficient to mimic the null phenotype, where expression in a different pair of neurons is sufficient to rescue the null animals, has been discussed previously and may result from overexpression during rescue (Mills et al., 2012). Together, these data suggest that NPR-17 functions at multiple sites, including the ASIs, AUAs, and PVPs, to modulate aversive responses.

\section{NPR-17 signaling requires $\mathrm{G} \alpha_{\mathrm{o}}$ in the ASIs}

Signaling from mammalian KORs is complex, with both $\mathrm{G} \alpha_{\mathrm{o} / \mathrm{i}}$ and MAP kinases involved (Prather et al., 1995). To date, only one ortholog of the mammalian $\mathrm{G} \alpha_{\mathrm{o} / \mathrm{i}}$ subunit, encoded by goa-1, has been identified in C. elegans (Mendel et al., 1995; Ségalat et al., 1995). To determine whether NPR-17 potentially couples to
$\mathrm{G} \alpha_{\mathrm{o} / \mathrm{i}}$, goa- 1 was selectively knocked down using RNAi. The RNAi knockdown of goa- 1 in all NPR-17-expressing neurons, using the $n$ pr-17 promoter or, specifically in the ASIs, using either the srg-47 or gpa-4 promoters, had no effect on basal aversive responses off food but abolished morphine or 5-HT-dependent stimulation (Fig. 4). These data suggest that, like the human opiate receptors, $\mathrm{G} \alpha_{\mathrm{o} / \mathrm{i}}$ may also be involved in NPR-17 signaling.

\section{npr-17-null phenotypes could also be rescued by the} expression of the human KOR in the ASIs

Even though NPR-17 and the human KOR exhibited limited amino acid sequence identity $(<25 \%)$, morphine-modulated aversive responses could also be rescued in npr-17-null animals by the ASI expression of the human KOR (OPKR-1) (Fig. 5A). This result suggests that $C$. elegans contains endogenous peptides that also activate the human KOR or that the KOR is constitu- 


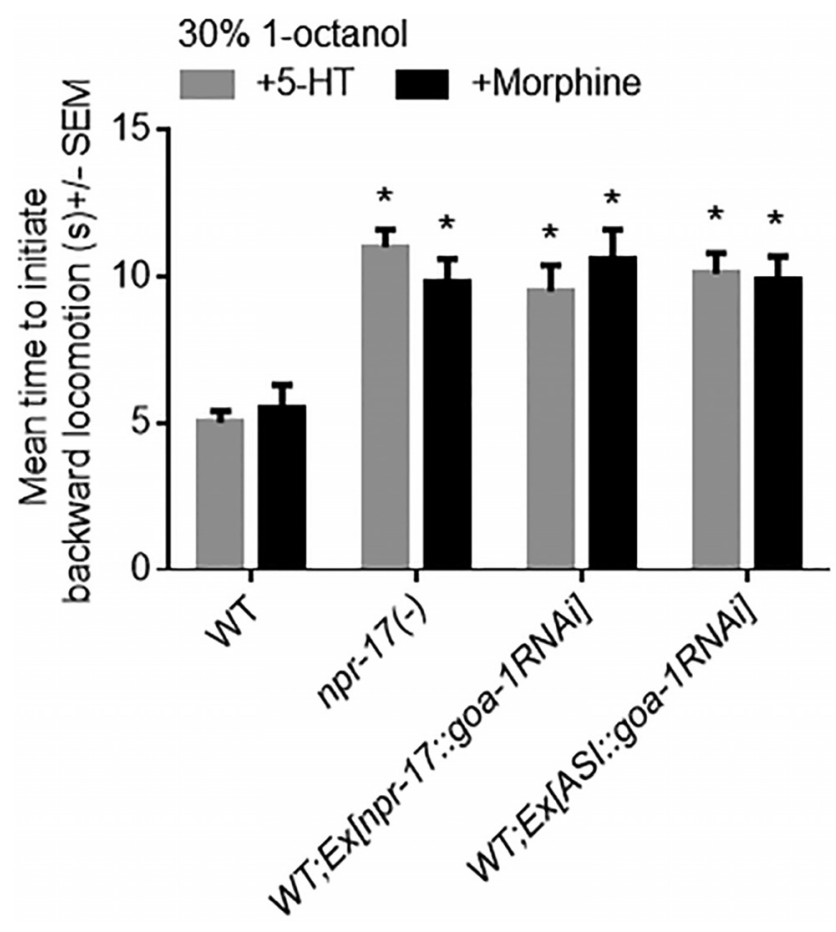

Figure 4. NPR-17 is a $\mathrm{G} \alpha_{0}$-coupled receptor. Aversive responses to 1-octanol were measured in the presence and absence of $4 \mathrm{~mm} 5$-HT or $320 \mu \mathrm{m}$ morphine in wild-type and animals expressing goa-1 RNAi. The srg-47 promoter was used to drive expression in the ASIs. Data are mean \pm SEM, with 15-20 animals being tested in three independent experiments. ${ }^{*} p<$ 0.0001 significantly different from wild-type animals under identical conditions (two-tailed Student's $t$ test).

tively active under these expression conditions. Human KORs are activated by endogenous Dynorphin (Dyn) peptides (O'Connor et al., 2015). Therefore, to determine whether endogenous mammalian KOR ligands could activate NPR-17, Dyn-A was injected into the pseudocoelom of wild-type and npr-17-null animals. As predicted, Dyn-A injection into wild-type, but not npr-17-null, animals mimicked morphine or 5-HT and stimulated the initiation of the aversive response (Fig. $5 B$ ). Together, these data strongly support previous observations that NPR-17 is a opioidlike receptor and that $C$. elegans contains endogenous opioidreceptor ligands (Cheong et al., 2015).

\section{NPR-17 functions in the ASI sensory neurons and appears to selectively inhibit a tyramine-mediated peptidergic signaling cascade}

The monoaminergic inhibition of ASH-mediated aversive responses is focused on the two ASIs (Mills et al., 2012; Hapiak et al., 2013). For example, TA abolishes the food or 5-HT modulation of responses to $30 \% 1$-octanol and requires (1) the $\mathrm{G} \alpha_{\mathrm{q}}$ coupled TA receptor TYRA-3 and (2) neuropeptides encoded by $n l p-1,-14$, and -18 in the ASIs. Similarly, the OA modulation of aversive responses to $100 \%$ 1-octanol requires (1) the $\mathrm{G} \alpha_{\mathrm{q}}$ coupled OA receptor SER-6 and (2) the neuropeptide-encoding genes $n l p-6,-7$, and -9 in the ASIs (Mills et al., 2012; Hapiak et al., 2013). We hypothesized that ASI NPR-17-mediated $\mathrm{G} \alpha_{\mathrm{o}}$ signaling might inhibit the release of these modulatory neuropeptides from the ASIs. Therefore, NPR-17 or the human KOR OPKR-1 was selectively overexpressed in the ASIs of wild-type animals. Interestingly, although the overexpression of full-length $n$ pr-17 genomic transgene stimulated the initiation of aversive responses to 1-octanol off food, the ASI overexpression of
NPR-17 or OPKR-1 had no effect on basal aversive responses, suggesting that additional NPR-17-expressing neurons were involved in more rapid initiation observed after npr-17 overexpression, as suggested above (Fig. 6). Surprisingly, the ASI overexpression of either NPR-17 or OPKR-1 abolished the TA, but not OA modulation of aversive responses. Conversely, TA, but not $\mathrm{OA}$, also abolished the morphine-modulation of aversive responses (Fig. 6). Together, these data highlight the delicate balance of monoaminergic/peptidergic signaling and that ASI NPR-17 signaling might selectively inhibit the TA, but not the OA-dependent release of ASI neuropeptide.

Neuropeptides encoded by both $n l p-3$ and $n l p-24$ are required for the 5-HT and NPR-17-mediated modulation of aversive responses to 1 -octanol

To identify the neuropeptides involved in NPR-17 signaling, we screened a large number of neuropeptide-null animals for phenotypes identical to $n p r-17$-null animals. Using this approach, we identified two genes, $n l p-3$ and $n l p-24$, whose null alleles mimicked npr-17-null animals (i.e., aversive responses to dilute 1-octanol were not modulated by 5-HT) (Harris et al., 2010). In addition, (1) both neuropeptide-null animals were rescued by the expression of the appropriate genomic transgene; (2) $n l p-3$ or $n l p-24$ overexpression mimicked $n p r-17$ overexpression and yielded animals that initiated basal aversive responses more rapidly that wild-type animals; (3) $n l p-3$ or $n l p-24$ overexpression phenotypes were absent in npr-17-null animals; and (4) morphine stimulated aversive responses in both $n l p-3$ and $n l p-24$ null animals (Fig. 7). Together, these data suggest that peptides from both $n l p-3$ and $n l p-24$ are capable of activating NPR-17 or that they act in series or parallel as part of a larger peptidergic signaling cascade. Importantly, $n l p-24$ neuropeptides exhibit weak identity to human dynorphin, a ligand for the human $\kappa$ opioid receptor, with each peptide containing a conserved YGG motif (Nathoo et al., 2001). In contrast, $n l p-3$ neuropeptides do not. In addition, one of the six $n l p-24$ neuropeptides actives NPR-17 heterologously expressed in mammalian cells, and a different $n l p-24$ neuropeptide activates the human $\kappa$ opioid receptor expressed under similar conditions, suggesting that the neuropeptides encoded by nlp-24 may function physiologically as ligands for NPR-17, although it is unclear why only one of the six peptides was active in these assays (Cheong et al., 2015).

Neuropeptides encoded by $n l p-3$ potentially function extrasynaptically to enhance aversive responses

Given that neuropeptides encoded by $n l p-24$ appeared to activate NPR-17, we examined the role of $n l p-3$ modulation more thoroughly. Previous work has demonstrated that $n l p-3$ expression in the two ASH sensory neurons is essential for the 5-HT modulation of the aversive response, based on ASH nlp-3 RNAi knockdown (Harris et al., 2010). In addition to the ASHs, $n l p-3:: g f p$ expression is also observed in a number of other sensory neurons (Nathoo et al., 2001). Therefore, to better understand $n l p-3$ mediated peptidergic signaling, $n l p-3$ was selectively rescued and overexpressed in additional pairs of sensory neurons endogenously expressing $n l p-3$ (Fig. 8). Surprisingly, the 5-HT modulation of 1-octanol-dependent aversive responses could be rescued in $n l p-3$ null animals by selective $n l p-3$ expression/overexpression using promoters that drive expression in neurons including the ASHs, AWBs, BAGs, or NSMs (Fig. 8). In contrast, selective $n l p-3$ expression in the ASJ or ASE neurons did not rescue 5-HT modulation. Conversely, selective $n l p-3$ overexpression in the 
A

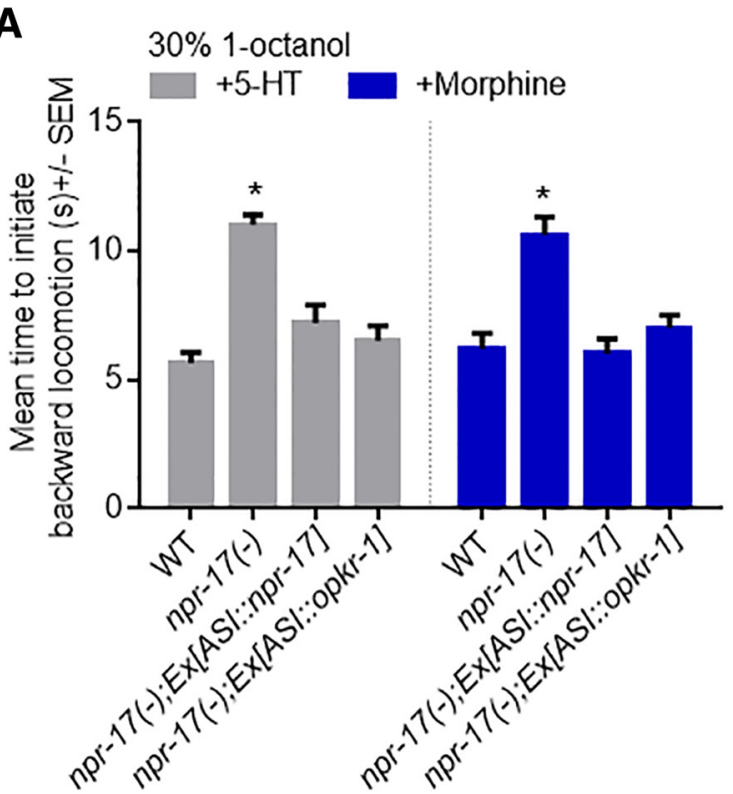

B

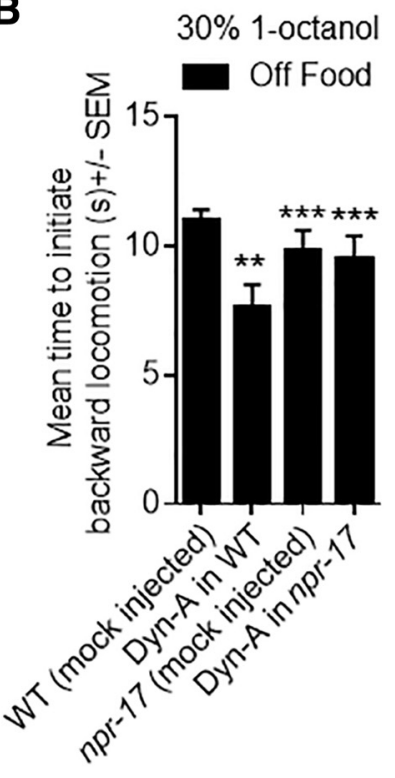

Figure 5. Aversive responses can be restored by expression of the human KOR in npr-17-null animals. $\boldsymbol{A}$, Aversive responses to 1-octanol were measured in the presence and absence of $4 \mathrm{~mm} 5$ - $\mathrm{HT}$ or $320 \mu \mathrm{m}$ morphine in wild-type and transgenic animals. The srg-47 promoter was used to drive expression in the ASIs. $\boldsymbol{B}$, Aversive responses to 1-octanol were measured in animals $10 \mathrm{~min}$ after injection of DYN-A (10 mm) peptide. Data are mean \pm SEM, with 15-20 animals being tested in three independent experiments. ${ }^{*} p<0.0001$ significantly different from wild-type animals under identical conditions (two-tailed Student's $t$ test). ${ }^{* *} p=0.0027$, significantly different from mock-injected animals (two-tailed Student's $t$ test). ${ }^{* * *} p=0.0087$, significantly different from wild-type animals injected with DYN-A (two-tailed Student's $t$ test).

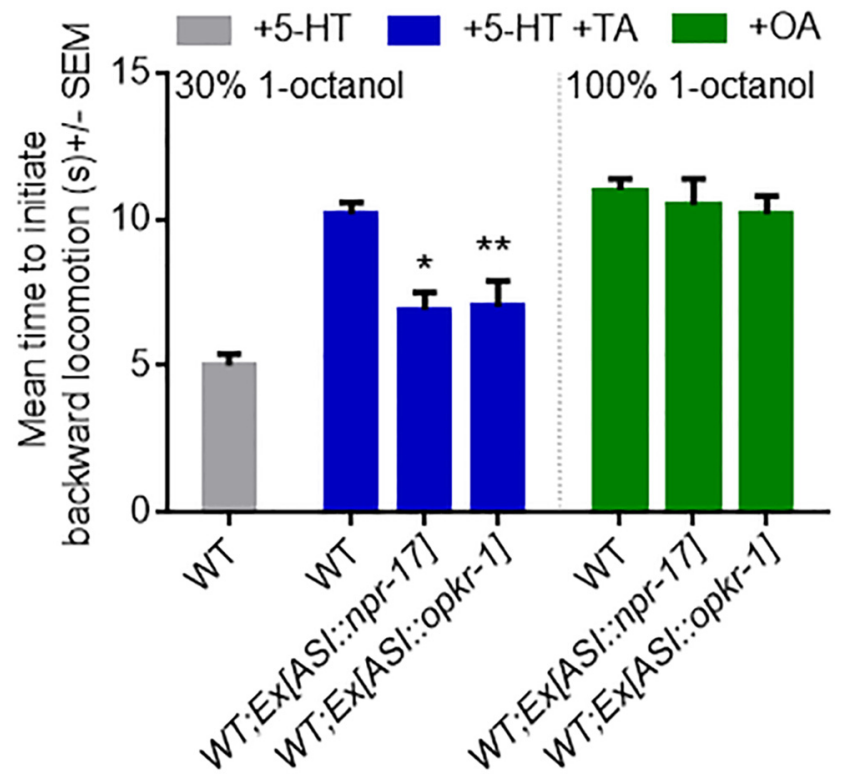

Figure 6. NPR-17 modulates TA but not OA signaling in the ASIs. $A, B$, Aversive responses to 1-octanol were measured in the presence and absence of $4 \mathrm{~mm} 5$ - $\mathrm{HT}$ or $4 \mathrm{~mm} \mathrm{TA}$ and $4 \mathrm{~mm} 5$-HT or $4 \mathrm{~mm} 0 \mathrm{~A}$. The $\mathrm{srg}-47$ promoter was used to drive expression in the ASIs. Data are mean \pm SEM, with $15-20$ animals being tested in three independent experiments. ${ }^{*} p=0.0012$, significantly different from wild-type animas under identical conditions (two-tailed Student's $t$ test). ${ }^{* *} p=0.0199$, significantly different from wild-type animas under identical conditions (two-tailed Student's $t$ test).

two ASHs, ASEs, ASJs, AWBs, BAGs, or NSMs of wild-type animals mimicked 5-HT and stimulated the initiation of the aversive response from $\sim 10$ to $5 \mathrm{~s}$ (Fig. 8). Perhaps the low-volume release of $n l p-3$ peptides from the ASJs and ASEs is insufficient to rescue 5-HT modulation, whereas $n l p-3$ selective overexpression cou-

pled to endogenous release from other neurons results in high-volume release capable of more robust diffusion and/or the saturation of extracellular peptidases. These data suggest that locally/ humorally released $n l p-3$-encoded neuropeptides potentially function extrasynaptically and modulate the activity state of the aversive circuit.

Peptides encoded by $n l p-3$ differentially modulate aversive responses

The $n l p-3$ gene encodes three different peptides: two are closely related, NLP-3.1 (AINPFLDSMG) and NLP-3.2 (AVNP FLDSIG); and one is distinct, NLP-3.3 (YFDSLAGQSLG). Each has been isolated directly from $C$. elegans and characterized by Q-TOF MS/MS (Nathoo et al., 2001; Husson and Schoofs, 2007). Importantly, in common with NPR-17, these nlp-3 peptides are also highly conserved among nematodes, with NLP-3.3 identical in nematodes as diverse as C. elegans, Ascaris suum, and filarial parasites, such as Loa loa (Fig. 9A).

To determine which of the nlp-3encoded peptides is required for the 5-HT-dependent modulation of aversive responses to 1-octanol, peptides were injected individually into wild-type animals and 1-octanol avoidance assayed after $10 \mathrm{~min}$. Mock-injection or the injection of NLP-3.1 or NLP-3.2 had no effect on aversive responses. In contrast, the injection of NLP-3.3 mimicked exogenous 5-HT or $n l p-3$ overexpression and stimulated the initiation of the aversive response off food (Fig. 9B). This NLP-3.3 stimulation was short-lived and absent $20 \mathrm{~min}$ after injection, suggesting either that the peptide was rapidly degraded or the receptor desensitized/downregulated (Fig. 9B). Importantly, NLP-3.3 injection had no effect on aversive responses in $n p r-17$-null animals (Fig. 9B). Similarly, the injection of NLP-3.3 into nlp-3;npr17-null animals expressing an ASI::opkr-1 transgene also stimulated the initiation of basal aversive responses off food, suggesting that NLP-3.3 was capable of activating the KOR directly or that NPR-17/KOR signaling was required for NLP3.3-dependent activation.

Interestingly, the more rapid initiation of aversive responses observed after NLP-3.3 injection were absent when NLP-3.3 was coinjected with NLP-3.1, suggesting that NLP-3.1 might antagonize the action of NLP-3.3 (Fig. 9A,B). This apparent "inhibition" did not appear to result from increased amounts of peptide injected, as it was also apparent when the concentrations of both peptides were halved (Fig. 9B). To further define a role for these potentially inhibitory $n l p-3$ peptides, an $n l p-3$ transgene was constructed that included NLP-3.1 and 3.2, but not 3.3. As predicted, the expression of this transgene had no effect on aversive responses off food but abolished 5-HT modulation (Fig. 9C). Together, these data suggest that the effects of $n l p-3$ signaling are rapid, short-lived, not the result of developmental compensation, require NPR-17, and that individual peptides encoded by the same gene have the potential to have antagonistic effects on individual behaviors. 
Neuropeptide signaling by $n l p-3$ and $n l p-24$ interacts to positively modulate ASH-mediated aversive responses to 1-octanol

As noted above, $n l p-3, n l p-24$, and $n p r-17$ are all required for the 5-HT stimulation of aversive responses, with $n l p-3$ and $n l p-24$ overexpression phenotypes absent in $n p r-17-n u l l$ animals. Because $n l p-24$ appears to encode ligands for NPR-17 (Cheong et al., 2015), these data suggest that $n l p-3$ might act upstream or in parallel to $n l p-24$. Importantly, $n l p-3$ overexpression phenotypes (i.e., more rapid initiation of aversive responses than wildtype animals off food) were absent in an $n l p-24$ null background, and $n l p-24$ overexpression phenotypes were absent in an $n l p-3$ null background, suggesting that that the two neuropeptide signaling pathways may act in parallel to modulate aversive responses (Fig. 10). Together, these data highlight the complexity of peptidergic modulation and the complex interaction of $n l p-3$ and $n l p-24$-dependent neuropeptide signaling in the modulation of aversive responses.

5-HT appears to stimulate the release of $n l p$-24-encoded peptides from the two ASI sensory neurons

An $n l p-24:: g f p$ transgene is expressed in the spermatheca and the two ASI sensory neurons (Nathoo et al., 2001), and previous work has suggested that nlp-24 peptides might be secreted and sensed by the ASIs (Cheong et al., 2015). As predicted, the ASI::RNAi knockdown of $n l p-24$ abolished the serotonergic modulation of aversive responses (Fig. 11). As noted above, 5-HT appears to act upstream of $n l p-24$; therefore, the $\mathrm{G} \alpha_{\mathrm{s}^{-}}$and $\mathrm{G} \alpha_{\mathrm{q}^{-}}$ coupled 5-HT receptors SER-7, SER-1, and SER-5 were selectively knocked down in the ASIs of wild-type animals, on the assumption that 5-HT stimulated the release of $n l p-24$ peptides. The ASI RNAi knockdown of ser-5 or ser-7 had no effect on serotonergic modulation (Fig. 11). This result suggests that the RNAi did not spread significantly from the ASIs, as ser- 5 null animals fail to respond to 5-HT in aversive assays (Harris et al., 2009; 2010). In contrast, the ASI RNAi knockdown of ser-1 mimicked $n l p-24$ null animals and abolished serotonergic modulation (Fig. 11). Together, these results suggest that 5-HT activates SER-1 on the ASIs, stimulates the release of $n l p$-24-encoded peptides that in turn activate ASI NPR-17, and selectively inhibits the release of TA-dependent neuropeptides (Fig. 12).

\section{Discussion}

The present study demonstrates that opioid receptor agonists act through the opioid-like receptor NPR-17 to modulate chemical

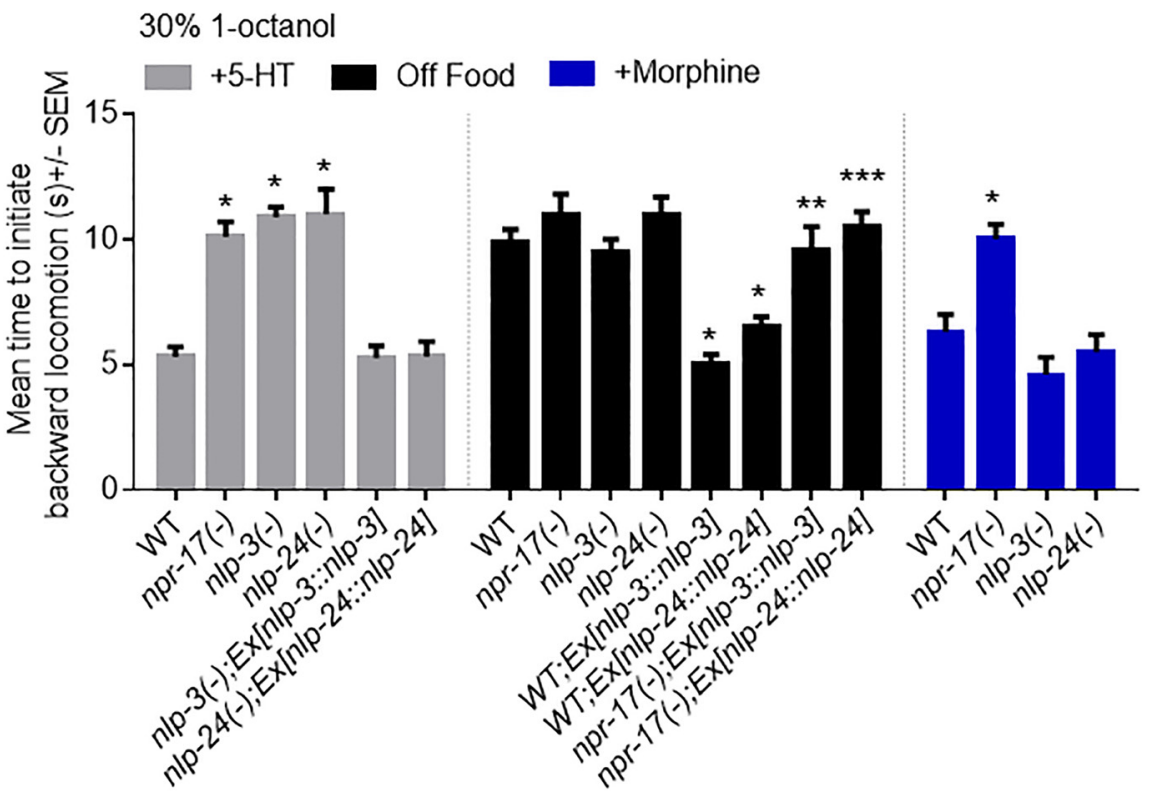

Figure 7. NLP-3 and NLP-24 require NPR-17 to modulate 1-octanol avoidance. Aversive responses to 1-octanol were measured off food or in the presence of $4 \mathrm{~mm} 5$-HT or $320 \mu \mathrm{m}$ morphine in wild-type, null, and transgenic animals. Data are mean \pm SEM, with 15-20 animals being tested in three independent experiments. ${ }^{*} p>0.0001$, significantly different from wild-type animals under identical conditions (two-tailed Student's $t$ test). ${ }^{* *} p=0.0012$, significantly different from wild-type animals expressing the same transgene (two-tailed Student's $t$ test). ${ }^{* *} p=0.0022$, significantly different from wild-type animals expressing the same transgene (two-tailed Student's t test).

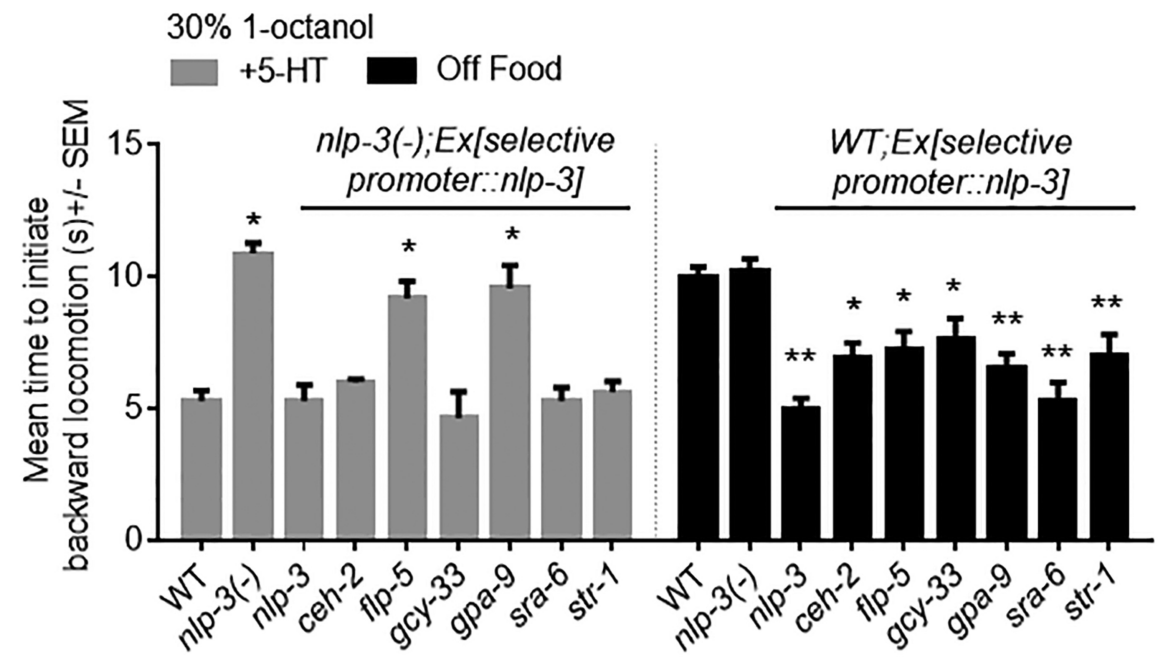

Figure 8. Peptides encoded by $n / p-3$ are expressed in multiple sensory neurons that modulate ASH-mediated aversive responses. Transgenes composed of a neuron-selective promoter fused to $n / p-3$ cDNA were injected into either wild-type or $n / p$-3null animals. Aversive responses to 1-octanol were measured off food or in the presence of 4 mM 5-HT. ceh-2 (NSM, I3, M3, M4); flp-5 (ASE, PVT, RMG, I4); gcy-33 (BAG); gpa-9 (ASJ, PHB, PVQ); sra-6 (ASH, ASI, PVQ); str-1 (AWB). Data are mean \pm SEM, with 15-20 animals being tested in three independent experiments. ${ }^{*} p<0.001$, significantly different from wild-type animals under identical conditions (two-tailed Student's $t$ test). ${ }^{* *} p<0.0001$, significantly different from wild-type animals under identical conditions (two-tailed Student's $t$ test). nociception in C. elegans through a complex signaling cascade involving both monoamines and neuropeptides. Although opioid agonists stimulate the initial withdrawal from the noxious stimulus, they induce the animals to continue to move forward in the face of the repellant, in keeping with their proposed role in pain suppression.

In mammals, KORs interact primarily with inhibitory $\mathrm{G} \alpha$ subunits and KOR agonists inhibit adenylyl cyclase, and decrease SV/DCV release by inhibiting neuronal $\mathrm{Ca}^{2+}$ currents, mediated 
A

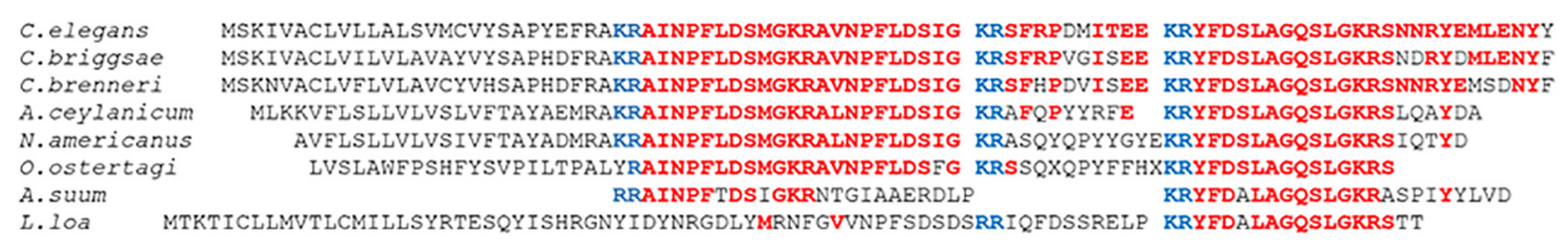

$30 \% 1$-octanol
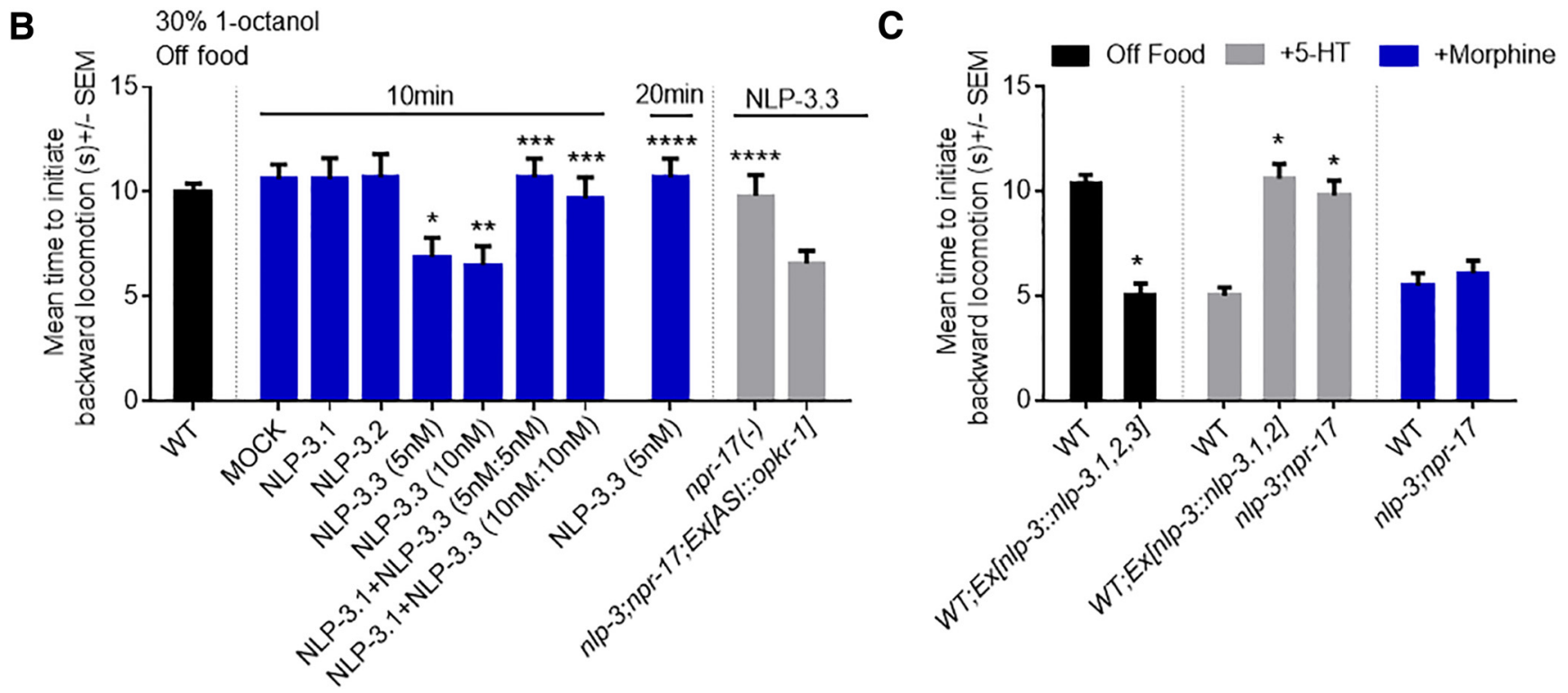

Figure 9. nIp-3-encoded peptides differentially modulate ASH-mediated 1-octanol aversive responses. A, Annotated NLP-3 protein sequences were obtained using NCBI blast and were aligned using Clustal Omega. Red represents identical amino acids. Blue represents potential dibasic cleavage sites. $\boldsymbol{B}$, Aversive responses to 1-octanol were measured off food either 10 or 20 min after injection. C, Aversive responses to 1-octanol were measured off food or in the presence of $4 \mathrm{~mm} 5$-HT or $320 \mu \mathrm{m}$ morphine in wild-type, double mutants, and transgenic animals. Data are mean \pm SEM, with $15-20$ animals being tested in three independent experiments. ${ }^{*} p<0.0001$, significantly different from mock-injected animals (two-tailed Student's $t$ test). ${ }^{* *} p<0.01$, significantly different from mock-injected animals (two-tailed Student's $t$ test). ${ }^{* * *} p<0.01$, significantly different from animals injected with NLP-3.3 only (two-tailed Student's $t$ test). ${ }^{* * * *} p<0.0001$, significantly different from wild-type animals injected with only NLP-3.3 after $10 \mathrm{~min}$ (two-tailed Student's $t$ test).

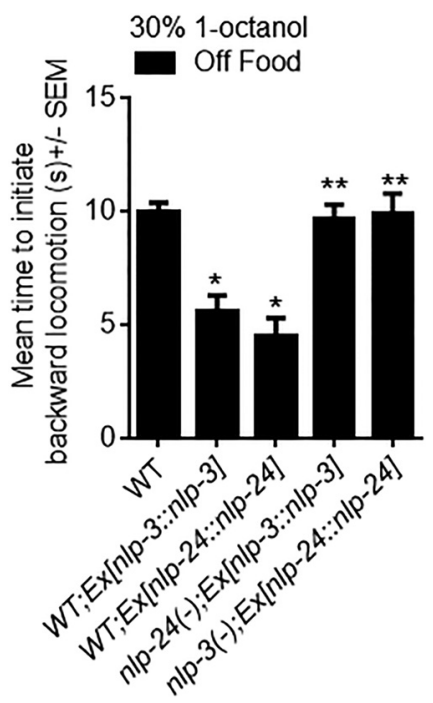

Figure 10. Both $n / p-3$ and $n l p-24$ are essential for aversive responses. Aversive responses to 1-octanol were measured off food in wild-type, double mutants, and transgenic animals. Data are mean \pm SEM, with $15-20$ animals being tested in three independent experiments. ${ }^{*} p<$ 0.0001 , significantly different from wild-type animals under identical conditions (two-tailed Student's $t$ test). ${ }^{* *} p<0.0001$, significantly different from wild-type animals overexpressing the same transgene (two-tailed Student's $t$ test). at least in part by G-protein $\beta \gamma$ subunits. KOR signaling also activates MAPK kinases, so that the effects of KOR signaling can be both acute and chronic, mediated by rapid changes in neuronal excitability and gene expression, respectively. The present study suggests that ASI NPR-17 signaling may selectively inhibit peptide release from the ASIs. In mammals, KORs are expressed at all levels of the hypothalamic/hypophaseal axis and are involved in stress, mood, feeding, and nociception (Calogero et al., 1996; Knoll and Carlezon, 2010; Vadivelu et al., 2011; Van't Veer and Carlezon, 2013; Sudakov et al., 2014). Interestingly, the $C$. elegans peptidergic ASIs are involved in a multineuron, multipeptide signaling cascade that mimics the mammalian hypothalamic/hypophaseal axis, with the peptidergic ASIs contributing significantly to "behavioral state" by releasing an array of peptides that are broadcast widely to differentially modulate individual behaviors.

Neuropeptides encoded by $n l p-3$ and $n l p-24$ are both required for the 5-HT modulation of aversive responses to 1-octanol Neuropeptides encoded by both $n l p-3$ and $n l p-24$ are required for the 5-HT modulation of aversive responses and feeding in $C$. elegans (Harris et al., 2010; Cheong et al., 2015). 5-HT appears to stimulate the release of $n l p-24$ peptides from the ASIs that, in turn, activate ASI NPR-17. ASI NPR-17 then selectively inhibits the TA/TYRA-3-dependent-release of ASI neuropeptides 
(Hapiak et al., 2013). In addition, NPR-17 also functions on additional neurons modulating the ASH-mediated locomotory circuit. In contrast, $n l p-3$ peptides appear to act in parallel to $n l p-$ $24 / n p r-17$, as $n l p-3$ overexpression phenotypes are absent in nlp-24 or $n p r$-17-null animals.

The extensive interactions between peptidergic and monoaminergic signaling pathways have hindered attempts to identify the NLP-3 receptor. Given that $n l p-3$ is expressed in a number of sensory neurons, we hypothesize that NLP-3 may integrate sensory information into the locomotory circuit. This level of complexity, in a "simple" model organism, was unexpected, with multiple monoamines and neuropeptides involved and highlights the utility of $C$. elegans for modeling the complex interactions between monoaminergic and peptidergic signaling involved in the opiate-dependent modulation of nociception.

\section{Extrasynaptic neuropeptide release modulates behavioral state}

Because $n l p-3$ null phenotypes can be rescued in different sensory neurons and $n l p-3$ overexpression phenotypes are apparent when expressed in any sensory neurons expressing $n l p-3:: g f p, n l p-3$ peptides may function extrasynaptically to modulate the aversive circuit. Indeed, the release of neuropeptides from dense-core vesicles is not restricted to synaptic specializations (Ludwig et al., 2002; Ludwig and Pittman, 2003; Fuenzalida et al., 2011). Neuropeptides can diffuse long distances with peptidergic fibers and receptors often found in spatially distinct regions of the brain, with peptidergic signaling enhanced by long half-lives compared with classical transmitters, high-affinity receptors, and post-translational modifications designed to prevent degradation. Indeed, the wiring diagram only presents a static picture of a dynamic situation, and subsets of synapses can be selected by contextdependent changes in internal state mediated by an array of neuromodulators, suggesting a delicate balance between lo$\mathrm{cal} /$ humoral pools of synergistic/antagonistic monoamines and neuropeptides. Subtle changes in monoaminergic or peptidergic signaling can result in significant behavioral changes. For example, in C. elegans, numerous peptide/receptor overexpression phenotypes have been identified, and only twofold changes in the expression of a TA receptor were sufficient to alter locomotory behaviors (Bendesky et al., 2011). Similarly, increasing the ratio of CRF1/ CRF2 receptors increased fear responses in rats (Elharrar et al., 2013; Zheng et al., 2013). Together, these studies highlight the complexities of peptidergic modulation.

\section{Neuropeptides encoded by the same gene can have} antagonistic effects on behavior.

$n l p-3$ encodes three neuropeptides, but only NLP-3.3-3 mimics $n l p-3$ overexpression to stimulate aversive responses. Indeed, NLP-3.1 appears to abolish both 5-HT and NLP-3.3 stimulation. The opposing activities of these two nlp-3 peptides could be mediated by the same receptor, with NLP-3.1 and NLP-3.3 competing for a common binding site, or alternatively, NLP-3.1 could activate a second receptor modulating the locomotory circuitry.

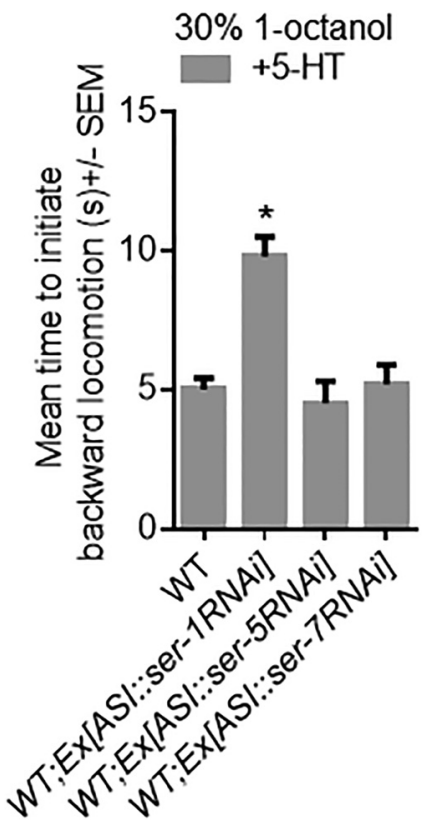

Figure 11. SER-1 is expressed in the ASIs and is essential for 5-HT-stimulated aversive responses. Aversive responses to 1-octanol were measured off food in wild-type and transgenic animals. The srg- 47 promoter was used to drive expression in the ASIs. Data are mean \pm SEM, with $15-20$ animals being tested in three independent experiments. ${ }^{*} p<0.0001$, significantly different from wild-type animals under identical conditions (two-tailed Student's $t$ test).

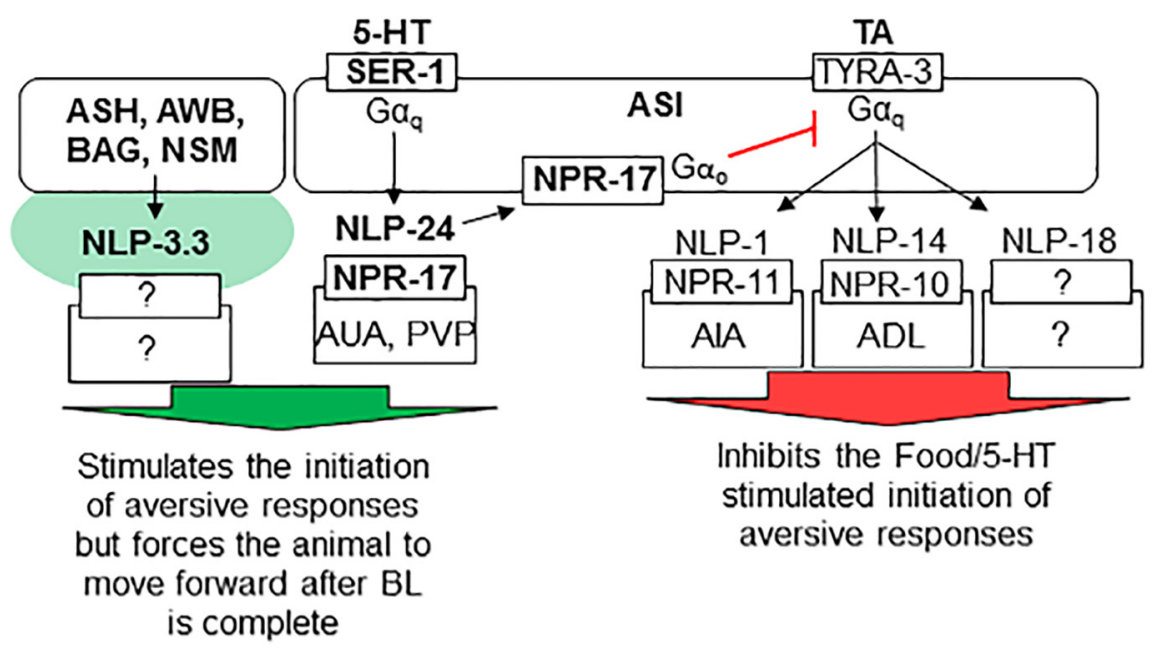

Figure 12. The opioid-like receptor NPR-17 is required in the ASIs to modulate ASH-mediated aversive responses.

Indeed, most peptide-encoding genes encode multiple peptides, each with potentially different properties. For example, although Dyn-A, Dyn-B, and $\alpha$-neoendorphin are potent KOR agonists, Dyn-A and Dyn-B cause more KOR internalization and downregulation than $\alpha$-neoendorphin (Chen et al., 2007). Peptides encoded by the same gene may also activate different receptors. For example, C. elegans flp-18 neuropeptides activate NPR-1, NPR-14, and NPR-5 to modulate social feeding, foraging, and metabolism (Rogers et al., 2003; Cohen et al., 2009).

Because $n l p-3$ encoded peptides are potentially released extrasynaptically and probably degraded rapidly, based on the short half-life of NLP-3.3 stimulation, this arrangement could provide additional levels of modulation, with distinct local/humoral pools with different NLP-3.1/3.3 ratios, dependent on the relative placement and specificity of the different peptide-degrading 
peptidases. These studies raise intriguing questions approximately the constraints that limit the transmission and precision of peptidergic signaling.

\section{The ASIs receive modulatory inputs from three different monoamines}

Food modulates aversive responses by stimulating the local/humoral release of 5-HT from the serotonergic NSM neurons, which, in turn, activates distinct 5-HT receptors throughout the locomotory circuit (Harris et al., 2009, 2011). In wild-type animals, these 5-HT receptors are essential for food/5-HT stimulation, but in various null backgrounds the absence of one receptor can be compensated for by the overexpression of another, suggesting that a complex interactive cascade of serotonergic signaling modulates the aversive machinery. In the present study, we have presented genetic evidence demonstrating that 5-HT activates a $\mathrm{G} \alpha_{\mathrm{q}}$-coupled 5-HT receptor SER-1, on the ASIs, stimulating the release of $n l p-24$ encoded peptides that, in turn, activate ASI NPR-17 to selectively inhibit the release of a third group of ASI peptides that inhibit 5-HT stimulation. The release of these ASI peptides is mediated by the $\mathrm{G} \alpha_{\mathrm{q}}$-coupled adrenergic-like TA receptor TYRA-3, and the receptors for these peptides appear be distributed throughout the locomotory circuit (Hapiak et al., 2013). Similarly, at higher levels of ASH stimulation, OA inhibits aversive responses by the activation of an additional ASI $\mathrm{G}_{\mathrm{q}^{-}}$ coupled receptor, SER-6, which stimulates the release of a completely different group of ASI peptides (Mills et al., 2012). These results suggest that three distinct $\mathrm{G} \alpha_{\mathrm{q}}$-coupled monoamine receptors are expressed on the ASIs that stimulate the release of distinct subsets of neuropeptides. Although these receptors heterologously couple to $\mathrm{G} \alpha$, they could couple to additional signaling pathways in vivo. In addition, ASI peptide release may be compartmentalized, with peptides localized to different DCVs and/or receptors. Indeed, although C. elegans neurons are isopotential, increases in internal $\mathrm{Ca}^{2+}$ may be required for DCV release that would be dependent on the position of L-type $\mathrm{Ca}^{2+}$ channels, such as EGL-19, and/or the release of $\mathrm{Ca}^{2+}$ from internal stores (Simmons et al., 1995; Sabatier et al., 1997; Ludwig et al., 2002; Zahratka et al., 2015). Indeed, $\mathrm{Ca}^{2+}$ signaling is localized in the RIA interneurons, with GAR-3, a G-protein coupled acetylcholine receptor, mediating independent $\mathrm{Ca}^{2+}$ events in ventral and dorsal axonal segments (Hendricks et al., 2012). Asynchronous $\mathrm{Ca}^{2+}$ events were also observed in the AIY interneurons (Clark et al., 2006; Chalasani et al., 2007). Spatially restricted $\mathrm{Ca}^{2+}$ signals are also observed in higher organisms. For example, bradykinin induces the release of internal $\mathrm{Ca}^{2+}$ at junctional microdomains leading to the activation of $\mathrm{Ca}^{2+}$-activated chloride channels (Jin et al., 2013). Although compartmentalized $\mathrm{Ca}^{2+}$ signals have only been reported in a couple of $C$. elegans neurons, genetic data from this study and others suggest that local $\mathrm{Ca}^{2+}$ signaling may be a more widespread phenomenon in C. elegans.

\section{Opioid signaling in other invertebrates}

The role of opioid signaling in modulating nociception in higher organisms has been extensively studied. However, less is known about its role in invertebrates. Interestingly, morphine and its active metabolite, M6G, have been isolated directly from the nematodes, Ascaris summ and Dracunculus medinesis (Pryor et al., 2005). The production of endogenous morphine in the parasites may be required to suppress host immune responses because morphine can act as an immunosuppressant. In C. elegans and $A$. suum, morphine also modulates thermal aversion. Interestingly, morphine had no effect on the initiation of "rapid reflex withdrawal" to heat but dramatically altered the postinitiation response, by inducing animals to backup less and continue moving forward, mimicking exactly the $C$. elegans aversive response to $100 \%$ octanol on 5-HT (Mills et al., 2012). Endogenous opioid signaling in nematodes may have been directed primarily at enhancing the withdrawal away from noxious stimuli, but in higher organisms has been expanded to also suppress the psychological perception of pain by downregulating the signaling pathways associated with pain perception, as evidenced by the ability of 5-HT or morphine to suppress reversal after the initiation of the aversive response.

\section{References}

Alizadeh Z, Fereidoni M, Behnam-Rassouli M, Hosseini S (2014) Role of $\mathrm{C}$-fibers in pain and morphine induced analgesia/hyperalgesia in rats. Iran J Neurol 13:19-27. Medline

Alkema MJ, Hunter-Ensor M, Ringstad N, Horvitz HR (2005) Tyramine functions independently of octopamine in the Caenorhabditis elegans nervous system. Neuron 46:247-260. CrossRef Medline

Aspöck G, Ruvkun G, Bürglin TR (2003) The Caenorhabditis elegans ems class homeobox gene ceh- 2 is required for M3 pharynx motoneuron function. Development 130:3369-3378. CrossRef Medline

Bendesky A, Tsunozaki M, Rockman MV, Kruglyak L, Bargmann CI (2011) Catecholamine receptor polymorphisms affect decision-making in C. elegans. Nature 472:313-318. CrossRef Medline

Brockie PJ, Madsen DM, Zheng Y, Mellem J, Maricq AV (2001) Differential expression of glutamate receptor subunits in the nervous system of Caenorhabditis elegans and their regulation by the homeodomain protein UNC-42. J Neurosci 21:1510-1522. Medline

Brenner S (1974) The genetics of Caenorhabditis elegans. Genetics 77:71-94. Medline

Calogero AE, Scaccianoce S, Burrello N, Nicolai R, Muscolo LA, Kling MA, Angelucci L, D’Agata R (1996) The kappa-opioid receptor agonist MR2034 stimulates the rat hypothalamic-pituitary-adrenal axis: studies in vivo and in vitro. J Neuroendocrinol 8:579-585. CrossRef Medline

Chalasani SH, Chronis N, Tsunozaki M, Gray JM, Ramot D, Goodman MB, Bargmann CI (2007) Dissecting a circuit for olfactory behaviour in Caenorhabditis elegans. Nature 450:63-70. CrossRef Medline

Chao MY, Komatsu H, Fukuto HS, Dionne HM, Hart AC (2004) Feeding status and serotonin rapidly and reversibly modulate a Caenorhabditis elegans chemosensory circuit. Proc Natl Acad Sci U S A 101:15512-15517. CrossRef Medline

Chen Y, Chen C, Liu-Chen LY (2007) Dynorphin peptides differentially regulate the human kappa opioid receptor. Life Sci 80:1439-1448. CrossRef Medline

Cheong MC, Artyukhin AB, You YJ, Avery L (2015) An opioid-like system regulating feeding behavior in C. elegans. eLife 4:06683. CrossRef Medline

Chou JH, Bargmann CI, Sengupta P (2001) The Caenorhabditis elegans odr-2 gene encodes a novel Ly-6-related protein required for olfaction. Genetics 157:211-224. Medline

Clark DA, Biron D, Sengupta P, Samuel AD (2006) The AFD sensory neurons encode multiple functions underlying thermotactic behavior in Caenorhabditis elegans. J Neurosci 26:7444-7451. CrossRef Medline

Cohen M, Reale V, Olofsson B, Knights A, Evans P, de Bono M (2009) Coordinated regulation of foraging and metabolism in C. elegans by RFamide neuropeptide signaling. Cell Metab 9:375-385. CrossRef Medline

Elharrar E, Warhaftig G, Issler O, Sztainberg Y, Dikshtein Y, Zahut R, Redlus L, Chen A, Yadid G (2013) Overexpression of corticotropin-releasing factor receptor type 2 in the bed nucleus of stria terminalis improves posttraumatic stress disorder-like symptoms in a model of incubation of fear. Biol Psychiatry 74:827-836. CrossRef Medline

Esposito G, Di Schiavi E, Bergamasco C, Bazzicalupo P (2007) Efficient and cell specific knock-down of gene function in targeted C. elegans neurons. Gene 395:170-176. CrossRef Medline

Fei YJ, Romero MF, Krause M, Liu JC, Huang W, Ganapathy V, Leibach FH (2000) A novel $\mathrm{H}(+)$-coupled oligopeptide transporter (OPT3) from Caenorhabditis elegans with a predominant function as a $\mathrm{H}(+)$ channel and an exclusive expression in neurons. J Biol Chem 275:9563-9571. CrossRef Medline

Fuenzalida LC, Keen KL, Terasawa E (2011) Colocalization of FM1-43, 
Bassoon, and GnRH-1: GnRH-1 release from cell bodies and their neuroprocesses. Endocrinology 152:4310-4321. CrossRef Medline

Gross E, Soltesz Z, Oda S, Zelmanovich V, Abergel Z, de Bono M (2014) GLOBIN-5-dependent O2 responses are regulated by PDL-1/PrBP that targets prenylated soluble guanylate cyclases to dendritic endings. J Neurosci 34:16726-16738. CrossRef Medline

Hapiak V, Summers P, Ortega A, Law WJ, Stein A, Komuniecki R (2013) Neuropeptides amplify and focus the monoaminergic inhibition of nociception in Caenorhabditis elegans. J Neurosci 33:14107-14116. CrossRef Medline

Harris GP, Hapiak VM, Wragg RT, Miller SB, Hughes LJ, Hobson RJ, Steven R, Bamber B, Komuniecki RW (2009) Three distinct amine receptors operating at different levels within the locomotory circuit are each essential for the serotonergic modulation of chemosensation in Caenorhabditis elegans. J Neurosci 29:1446-1456. CrossRef Medline

Harris G, Mills H, Wragg R, Hapiak V, Castelletto M, Korchnak A, Komuniecki RW (2010) The monoaminergic modulation of sensory-mediated aversive responses in Caenorhabditis elegans requires glutamatergic/peptidergic cotransmission. J Neurosci 30:7889-7899. CrossRef Medline

Harris G, Korchnak A, Summers P, Hapiak V, Law WJ, Stein AM, Komuniecki P, Komuniecki R (2011) Dissecting the serotonergic food signal stimulating sensory-mediated aversive behavior in C. elegans. PLoS One 6:e21897. CrossRef Medline

Hendricks M, Ha H, Maffey N, Zhang Y (2012) Compartmentalized calcium dynamics in a C. elegans interneuron encode head movement. Nature 487:99-103. CrossRef Medline

Herman RK, Hedgecock EM (1990) Limitation of the size of the vulval primordium of Caenorhabditis elegans by lin-15 expression in surrounding hypodermis. Nature 348:169-171. CrossRef Medline

Hobert O (2002) PCR fusion-based approach to create reporter gene constructs for expression analysis in transgenic C. elegans. Biotechniques 32: 728-730. Medline

Husson SJ, Schoofs L (2007) Processing of neuropeptide precursors in Caenorhabditis elegans. Commun Agric Appl Biol Sci 72:199-203. Medline

Jansen G, Thijssen KL, Werner P, van der Horst M, Hazendonk E, Plasterk RH (1999) The complete family of genes encoding G proteins of Caenorhabditis elegans. Nat Genet 21:414-419. CrossRef Medline

Jin X, Shah S, Liu Y, Zhang H, Lees M, Fu Z, Lippiat JD, Beech DJ, Sivaprasadarao A, Baldwin SA, Zhang H, Gamper N (2013) Activation of the Cl- channel ANO1 by localized calcium signals in nociceptive sensory neurons requires coupling with the IP3 receptor. Sci Signal 6:ra73. CrossRef Medline

Kim K, Li C (2004) Expression and regulation of an FMRFamide-related neuropeptide gene family in Caenorhabditis elegans. J Comp Neurol 475: 540-550. CrossRef Medline

Knoll AT, Carlezon WA Jr (2010) Dynorphin, stress, and depression. Brain Res 1314:56-73. CrossRef Medline

Komuniecki R, Hapiak V, Harris G, Bamber B (2014) Context-dependent modulation reconfigures interactive sensory-mediated microcircuits in Caenorhabditis elegans. Curr Opin Neurobiol 29:17-24. CrossRef Medline

Kramer JM, French RP, Park EC, Johnson JJ (1990) The Caenorhabditis elegans rol-6 gene, which interacts with the sqt- 1 collagen gene to determine organismal morphology, encodes a collagen. Mol Cell Biol 10:20812089. CrossRef Medline

Ludwig M, Pittman QJ (2003) Talking back: dendritic neurotransmitter release. Trends Neurosci 26:255-261. CrossRef Medline

Ludwig M, Sabatier N, Bull PM, Landgraf R, Dayanithi G, Leng G (2002) Intracellular calcium stores regulate activity-dependent neuropeptide release from dendrites. Nature 418:85-89. CrossRef Medline

McGrath PT, Xu Y, Ailion M, Garrison JL, Butcher RA, Bargmann CI (2011) Parallel evolution of domesticated Caenorhabditis species targets pheromone receptor genes. Nature 477:321-325. CrossRef Medline

Mellem JE, Brockie PJ, Zheng Y, Madsen DM, Maricq AV (2002) Decoding of polymodal sensory stimuli by postsynaptic glutamate receptors in C. elegans. Neuron 36:933-944. CrossRef Medline

Mello C, Fire A (1995) DNA transformation. Methods Cell Biol 48:451482. CrossRef Medline

Mendel JE, Korswagen HC, Liu KS, Hajdu-Cronin YM, Simon MI, Plasterk RH, Sternberg PW (1995) Participation of the protein Go in multiple aspects of behavior in C. elegans. Science 267:1652-1655. CrossRef Medline

Mills H, Wragg R, Hapiak V, Castelletto M, Zahratka J, Harris G, Summers P, Korchnak A, Law W, Bamber B, Komuniecki R (2012) Monoamines and neuropeptides interact to inhibit aversive behaviour in Caenorhabditis elegans. EMBO J 31:667-678. CrossRef Medline

Morgan MM, Fossum EN, Stalding BM, King MM (2006) Morphine antinociceptive potency on chemical, mechanical, and thermal nociceptive tests in the rat. J Pain 7:358-366. CrossRef Medline

Nathoo AN, Moeller RA, Westlund BA, Hart AC (2001) Identification of neuropeptide-like protein gene families in Caenorhabditis elegans and other species. Proc Natl Acad Sci U S A 98:14000-14005. CrossRef Medline

O'Connor C, White KL, Doncescu N, Didenko T, Roth BL, Czaplicki G, Stevens RC, Wüthrich K, Milon A (2015) NMR structure and dynamics of the agonist dynorphin peptide bound to the human kappa opioid receptor. Proc Natl Acad Sci U S A 112:11852-11857. CrossRef Medline

Otsuka M, Yoshioka K (1993) Neurotransmitter functions of mammalian tachykinins. Physiol Rev 73:229-308. Medline

Prather PL, McGinn TM, Claude PA, Liu-Chen LY, Loh HH, Law PY (1995) Properties of a kappa-opioid receptor expressed in $\mathrm{CHO}$ cells: interaction with multiple G-proteins is not specific for any individual $\mathrm{G}$ alpha subunit and is similar to that of other opioid receptors. Brain Res Mol Brain Res 29:336-346. CrossRef Medline

Pryor SC, Henry S, Sarfo J (2005) Endogenous morphine and parasitic helminthes. Med Sci Monit 11:RA183-RA189. Medline

Rogers C, Reale V, Kim K, Chatwin H, Li C, Evans P, de Bono M (2003) Inhibition of Caenorhabditis elegans social feeding by FMRFamiderelated peptide activation of NPR-1. Nat Neurosci 6:1178-1185. CrossRef Medline

Salt TE, Hill RG (1983) Neurotransmitter candidates of somatosensory primary afferent fibres. Neuroscience 10:1083-1103. CrossRef Medline

Sabatier N, Richard P, Dayanithi G (1997) L-, N- and T- but neither P- nor Q-type $\mathrm{Ca}^{2+}$ channels control vasopressin-induced $\mathrm{Ca}^{2+}$ influx in magnocellular vasopressin neurones isolated from the rat supraoptic nucleus. J Physiol 503:253-268. CrossRef Medline

Ségalat L, Elkes DA, Kaplan JM (1995) Modulation of serotonin-controlled behaviors by Go in Caenorhabditis elegans. Science 267:1648-1651. CrossRef Medline

Simmons ML, Terman GW, Gibbs SM, Chavkin C (1995) L-type calcium channels mediate dynorphin neuropeptide release from dendrites but not axons of hippocampal granule cells. Neuron 14:1265-1272. CrossRef Medline

Stringham E, Pujol N, Vandekerckhove J, Bogaert T (2002) unc-53 controls longitudinal migration in C. elegans. Development 129:3367-3379. Medline

Sudakov SK, Nazarova GA, Alekseeva EV (2014) Changes in feeding behavior, locomotor activity, and metabolism in rats upon modulation of opioid receptors in the gastrointestinal tract. Bull Exp Biol Med 156:423425. CrossRef Medline

Summers PJ, Layne RM, Ortega AC, Harris GP, Bamber BA, Komuniecki RW (2015) Multiple sensory inputs are extensively integrated to modulate nociception in C. elegans. J Neurosci 35:10331-10342. CrossRef Medline

Troemel ER, Chou JH, Dwyer ND, Colbert HA, Bargmann CI (1995) Divergent seven transmembrane receptors are candidate chemosensory receptors in C. elegans. Cell 83:207-218. CrossRef Medline

Vadivelu N, Mitra S, Hines RL (2011) Peripheral opioid receptor agonists for analgesia: a comprehensive review. J Opioid Manag 7:55-68. CrossRef Medline

Van't Veer A, Carlezon WA Jr (2013) Role of kappa-opioid receptors in stress and anxiety-related behavior. Psychopharmacology (Berl) 229:435452. CrossRef Medline

Zahratka JA, Williams PD, Summers PJ, Komuniecki RW, Bamber BA (2015) Serotonin differentially modulates $\mathrm{Ca}^{2+}$ transients and depolarization in a C. elegans nociceptor. J Neurophysiol 113:1041-1050. CrossRef Medline

Zheng F, Kim YJ, Chao PT, Bi S (2013) Overexpression of neuropeptide Y in the dorsomedial hypothalamus causes hyperphagia and obesity in rats. Obesity 21:1086-1092. CrossRef Medline 